\title{
The use, misuse and abuse of dabigatran
}

\section{A number of issues need to be considered before using dabigatran routinely in clinical practice}

\section{to}

here has been much publicity and controversy about the role of dabigatran in the prevention of embolic stroke in those with atrial fibrillation since the landmark RE-LY (Randomized Evaluation of LongTerm Anticoagulation Therapy) trial was published in September 2009. ${ }^{1}$ In this perspective, we provide a critical appraisal of the original trial and highlight some concerns ("use"), review some of the issues about bleeding and inappropriate selection of patients ("misuse"), and detail some of the heated and unique politics around its attempted listing on the Pharmaceutical Benefits Scheme (PBS) in Australia ("abuse").

\section{Use of dabigatran}

A rigorous critical appraisal of the RE-LY trial reveals a few concerns.

Selection bias: Just under a third of participants enrolled in the trial had a $\mathrm{CHADS}_{2}$ (congestive heart failure, hypertension, age $\geqslant 75$ years, diabetes, 1 point each; prior stroke or transient ischaemic attack [TIA], 2 points) score of 0 or 1 . These people have a low risk of embolism $(0.5 \%-1.7 \%$ per year $)^{2}$ and are a group where the use of anticoagulation is considered as an option, and an "individualised" approach is recommended. ${ }^{3}$ Including low-risk participants for whom warfarin may be of marginal net benefit but who still carry the bleeding risk is likely to bias results in favour of dabigatran; this affects the internal validity of the trial, not just the generalisability.

Effect of co-interventions: About $40 \%$ of participants in the trial were concurrently taking aspirin and half of these (20\%) continued to take aspirin throughout the trial. Given the evidence that the combination of aspirin and warfarin increases the risk of bleeding and is only recommended in the setting of prosthetic valves, ${ }^{4}$ this would potentially have increased the risk of bleeding in the warfarin group. Although limited evidence would suggest that this risk may not be differential between warfarin and dabigatran, ${ }^{5}$ the rate of major bleeding in the RE-LY trial (over 3\% per year) is higher than the $1 \%-1.5 \%$ per year usually expected.

Adverse events: The original trial showed a significantly increased risk of myocardial infarction (MI) in the dabigatran group with a relative risk of 1.38 (95\% CI, 1.0-1.9, $P=0.048)$ compared with warfarin. Although it was noted that this was increased, it was described as being of uncertain significance. Revised outcomes were published for the RE-LY trial and included 28 previously unreported silent MIs, which tipped the balance away from the dabigatran group and reduced the relative risk to 1.27 ( $95 \% \mathrm{CI}, 0.94-1.71, P=0.12$ ).

Nevertheless, a recent meta-analysis pooling seven trials of dabigatran found a statistically increased risk of MI or acute
John R Attia MD, PhD, FRACP, Professor of Medicine and Clinical Epidemiology'

Robert Pearce BPharm, Director of Pharmacy ${ }^{2}$

1 Centre for Clinical Epidemiology and Biostatistics, University Newcastle, NSW.

2 John Hunter Hospital, Newcastle, NSW.

john.attia@ newcastle.edu.au

doi: 10.5694/mjal2.10729

9

(1)
(1) $17 \%)$. In a typical older community cohort, one would expect
prior MI to be about twice as prevalent as prior stroke or TIA. In generalising the results of the trial to a broader population, one might expect the absolute increase in cardiac risk with dabigatran to be even higher.

Conclusion: These issues all feed into a bias in favour of dabigatran, causing its benefit to be overstated when generalising to a broader population.

\section{Misuse of dabigatran}

Examples have already been published of patients who were in a stable condition while taking warfarin and who were switched to dabigatran with ensuing major bleeds. ${ }^{7}$ The United States Food and Drug Administration is also evaluating postmarketing reports of serious bleeding events in patients taking dabigatran. A number of issues need to be considered in deciding who is appropriate for dabigatran.

Stability on warfarin: Patients with a stable condition while taking warfarin, with no adverse events, should probably continue taking it. Two separate economic analyses show that where the international normalised ratio (INR) is therapeutic over $65 \%-70 \%$ of the time, the incremental cost-effectiveness ratio increases, making warfarin more cost-effective than dabigatran. ${ }^{8,9}$

Risk of bleeding: The effects of dabigatran cannot be pharmacologically reversed, but given that it is about onethird protein bound, it can be dialysed in patients with renal impairment, with about 60\% removed after 2-3 hours of dialysis. Work on an antidote is in process. Those who bleed while taking dabigatran are usually supported until the drug clears sufficiently from the system, unlike rivaroxaban or warfarin, which can be reversed with prothrombin complex concentrate or vitamin $\mathrm{K}$, respectively. ${ }^{10}$

Risk of cardiac disease: As stated earlier, dabigatran does not provide the same degree of cardioprotection as warfarin, and the underlying risk of cardiac disease must be considered. Perspective p 358 It may be the first agent that clinicians use that does not have 
a similar protective effect against cardiac and neurological risk. Those with moderate to high underlying cardiac risk must be considered for concomitant aspirin, although this must be weighed with the higher risk of bleeding, particularly gastrointestinal bleeding, with dabigatran.

Elderly patients: Dabigatran is renally excreted and must be used with caution in those with impaired renal function (estimated glomerular filtration rate [eGFR], 30-50 mL/min) and is contraindicated in those with renal failure (eGFR, $<30 \mathrm{~mL} / \mathrm{min}$ ). Elderly patients also have changes in lean body mass that are not captured in the eGFR.

Interacting drugs: Although dabigatran has a wide therapeutic range, it is a prodrug that is metabolised by the P-glycoprotein transporter, and hence drugs that interact with P-glycoprotein can increase dabigatran concentrations (eg, macrolides, amiodarone and verapamil) or reduce them (eg, rifampicin, carbamazepine and phenytoin). These considerations are especially important in the elderly.

Conclusion: Issues such as stability on warfarin, high risk of bleeding or cardiovascular disease, altered renal function and interactions with other drugs should be weighed when considering prescription of dabigatran, especially in the elderly.

\section{Abuse of dabigatran}

The potential market and profits for dabigatran are large; this provides considerable incentive to aggressively market a new product and has led to some heated politics, perhaps more extreme than any seen to date. We describe the politics and marketing of dabigatran in Australia as an example.

Listing on the PBS: In Australia alone, the Pharmaceutical Benefits Advisory Committee (PBAC) predicted costs to the PBS of over $\$ 100$ million by the 5 th year after the introduction of dabigatran, although there would be some savings with a reduction in INR testing. The PBAC recommended the listing of dabigatran but noted: "The listing of dabigatran may also result in patients at low risk currently managed on aspirin or no treatment being unnecessarily transferred to dabigatran at a much higher cost." ${ }^{11}$ Given the potentially significant financial impact of listing dabigatran and concerns about its place in the treatment of atrial fibrillation, the Minister for Health recommended a review of anticoagulant therapies in atrial fibrillation before any listing, with broad terms of reference that incorporated minimising harm, improving health outcomes, modifying health systems delivery and monitoring cost. This generated unprecedented criticism of the government. ${ }^{12}$ The proposed method of listing is possibly the cause of this criticism. The listing as "streamlined authority" means no phone call to regulating authorities is required. The PBAC itself admitted an inability to control prescribing: "Medicare Australia would not be able to enforce compliance with the risk factors under the requested 'streamlined' authority."11

Familiarisation programs: A PFP is designed with "the aim of allowing the medical profession to evaluate and become familiar with the product" ${ }^{13}$ Normally the medication would be limited to specialists in a particular field, with dispensing at hospital pharmacies. In the case of dabigatran, Boehringer Ingelheim launched an extensive outreach to general practitioners, shouldering the cost of dabigatran for 10 patients per GP until such time as the PBS approves the listing. In addition, copies of promotional material were sent to every registered medical practitioner in Australia, including hospital residents and advanced trainees. This went far beyond the usual scope of a PFP and could not be considered in keeping with the spirit of a PFP, but it did not formally breach the Medicines Australia guidelines.

Web campaign: Boehringer Ingelheim launched a website called "vote against stroke", which encouraged people to write to their member of parliament to protest the delay in approving dabigatran. This was seen as unduly coercive and was heavily criticised by the media and public, forcing the company to shut down the website. ${ }^{14}$

Conclusion: The marketing of dabigatran exemplifies a much broader marketing strategy than that usually seen in PFPs, and requires GPs to be much more informed about the evidence base.

\section{Summary}

The tale of dabigatran sounds some cautionary notes about proper critical appraisal of new randomised controlled trials, care in deciding on the generalisability of results, judicious screening of patients and lessons about the politics around increasingly lucrative drugs. The old lesson of caveat utilitor still holds: let the user beware!

Competing interests: No relevant disclosures.

Provenance: Not commissioned; externally peer reviewed.

1 Connolly SJ, Ezekowitz MD, YusufS, et al. Dabigatran versus warfarin in patients with atrial fibrillation. NEngl J Med 2009; 361: 1139-1151.

2 Gage BF, Waterman AD, Shannon W, et al. Validation of clinical classification schemes for predicting stroke: results from the National Registry of Atrial Fibrillation. JAMA 2001; 285: 2864-2870.

3 Fuster V, Rydén LE, Cannom DS, et al. ACC/AHA/ESC 2006 guidelines for the management of patients with atrial fibrillation: a report of the American College of Cardiology/American Heart Association Task Force on Practice Guidelines and the European Society of Cardiology Committee for Practice Guidelines (Writing Committee to Revise the 2001 Guidelines for the Management of Patients With Atrial Fibrillation): developed in collaboration with the European Heart Rhythm Association and the Heart Rhythm Society. Circulation 2006; 114: e257-e354.

4 Massel D, Little SH. Risks and benefits of adding anti-platelet therapy to warfarin among patients with prosthetic heart valves: a meta-analysis. J Am Coll Cardiol 2001; 37: 569-578.

5 Eikelboom JW, Wallentin L, Connolly SJ, et al. Risk of bleeding with 2 doses of dabigatran compared with warfarin in older and younger patients with atrial fibrillation: an analysis of the randomized evaluation of long-term anticoagulant therapy (RE-LY) trial. Circulation 2011; 123: 2363-2372.

6 Uchino K, Hernandez AV. Dabigatran association with higher risk of acute coronary events: meta-analysis of noninferiority randomized controlled trials. Arch Intern Med 2012; 172: 397-402.

7 Legrand M, Mateo J, Aribaud A, et al. The use of dabigatran in elderly patients. Arch Intern Med 2011; 171: 1285-1286.

8 Pink J, Lane S, Pirmohamed M, Hughes DA. Dabigatran etexilate versus warfarin in management of non-valvular atrial fibrillation in UK context: quantitative benefit-harm and economic analyses. BMJ 2011; 343:d6333.

9 Shah SV,Gage BF. Cost-effectiveness of dabigatran for stroke propylaxis in atrial fibrillation. Circulation 2011; 123: 2562-2570.

10 EerenbergES, KamphuisenPW, Sijpkens MK, et al. Reversal of rivaroxaban and dabigatran by prothrombin complex concentrate: a randomized, placebo-controlled, crossover study in healthy subjects. Circulation 2011; 124: 1573-1579.

11 Department of Health and Ageing. Public summary documents by product. Dabigatran etexilate, capsules, $110 \mathrm{mg}$ and $150 \mathrm{mg}$ (as mesilate), Pradaxa $($ - March 2011. http:// www.health.gov.au/internet/main/publishing.nst/Content/pbac-psd-dabigatranmarchll (accessed Nov 2012).

12 O'Brien M. GPs reveal big issues for 2012. Medical Observer 2011; 19 Dec. http:// www.medicalobserver.com.au/news/gps-reveal-big-issues-for-2012 (accessed Oct 2012).

13 Medicines Australia. Code of conduct - current edition. http:// medicinesaustralia.com.au/code-of-conduct/code-of-conduct-current-edition/ (accessed Nov 2012).

14 Dunlevy S. Pharma giant puts heat on Gillard after subsidy refusal. The Australian 2011; 3 Nov. http://www.theaustralian.com.au/national-affairs/health/pharma-giant-putsheat-on-gillard-after-subsidy-refusal/story-fn59nokw-1226184055515 (accessed Oct 2012). 